\title{
MULTI AKAD (HYBRID CONTRACT) INOVASI PRODUK LEMBAGA KEUANGAN SYARIAH
}

\author{
Shofy Liza Nurul Arafah ${ }^{1}$, Muhamad Yogi Hamdani ${ }^{2}$ \\ ${ }^{1}$ Prodi Ekonomi Syariah Pascasarjana UIN Sunan gunung Djati Bandung \\ ${ }^{2}$ Dosen Prodi Perbankan Syariah STIES Indonesia Purwakarta \\ ${ }^{1}$ sofy_lizana@gmail.com \\ ${ }^{2}$ yogirahmadin@gmail.com
}

\begin{abstract}
Intisari- Salah satu parameter untuk menilai suatu produk apakah telah memenuhi prinsip syariah atau tidak adalah dengan memperhatikan akad-akad dan berbagai ketentuannya yang digunakan dalam produk tersebut. Produk-produk dalam kegiatan keuangan syariah, jika terhadapnya dilakukan al-takyif al-fiqhi, beberapa atau bahkan sebagian terbesar ternyata mengandung beberapa akad. Sebagai contoh, dalam transaksi kartu kredit syariah terdapat akad ijarah, qardh, dan kafalah, obligasi syariah mengandung sekurang-kurangnya akad mudharabah (atau ijarah) dan wakalah, serta terkadang disertai kafalah atau wa'd, Islamic Swap mengandung beberapa kali akad tawarruq, bai', wakalah, sharf dan terkadang atau selalu disertai wa'ad. Dalam setiap transaksi, akad-akad tersebut dilakukan secara bersamaan atau setidak-tidaknya setiap akad yang terdapat dalam suatu produk tidak bisa ditinggalkan, karena kesemuanya merupakan satu kesatuan. Transaksi seperti itulah yang diistilahkan dengan multi akad (hybrid contract) yang kini dalam peristilahan fiqh muamalat kontemporer (fiqh al-mu'amalat al-maliyah al-mu'ashirah) disebut dengan al'uqud al-murakkabah.
\end{abstract}

Kata kunci- hybrid contract, lembaga keuangan syariah, multi akad.

Abstract - One of the parameters to assess whether a product meets sharia principles or not is to pay attention to the contracts and the various conditions used in the product. Products in Islamic finance activities, if against them are carried out by al-takyif al-fiqhi, some or even the majority of them contain several contracts. For example, in sharia credit card transactions there are ijarah, qardh and kafalah contracts, Islamic bonds contain at least mudharabah (or ijarah) and wakalah agreements, and sometimes with kafalah or wa'd, Islamic Swap contains several times the bargruq contract, bai ', wakalah, sharf and sometimes or always accompanied wa' ad. In every transaction, the contracts are carried out simultaneously or at least every contract contained in a product cannot be abandoned, because all of them are one entity. Such transactions are termed the multi contract (hybrid contract) which is now in the terminology of contemporary muamalat fiqh (fiqh al-mu'amalat al-maliyah al-mu'ashirah) called al-'uqud al-murakkabah.

Keywords - hybrid contract, Islamic financial institution, multi-contract.

\section{PENDAHULUAN}

Perkembangan perbankan dan keuangan syariah mengalami kemajuan yang sangat pesat dan menghadapi tantangan yang makin kompleks. Perbankan dan lembaga keuangan syariah harus bisa memenuhi kebutuhan bisnis modern dengan menyajikan produk-produk inovatif dan lebih variatif serta pelayanan yang memuaskan. Tantangan ini menuntut para praktisi, regulator, konsultan, dewan syariah dan akademisi bidang keuangan syariah untuk senantiasa aktif dan kreatif dalam memberikan respon terhadap perkembangan tersebut. Para praktisi dituntut secara kreatif melakukan inovasi produk, regulator membuat regulasi yang mengatur dan mengawasi produk yang dilaksanakan oleh praktisi, Dewan syariah dituntut secara aktif dan kreatif mengeluarkan fatwa-fatwa yang dibutuhkan industri sesuai tuntutan zaman, dan akademisi pun dituntut memberikan pencerahan ilmiah dan tuntunan agar produk maupun regulasi mendukung kebutuhan modern dan benar-benar tidak menyimpang dari prinsip-prinsip syariah.

Menurut Agustianto, fakta menunjukkan, bahwa inovasi produk perbankan syariah di Indonesia masih kurang dan masih jauh tertinggal. Produknya masih monoton dan bahkan terkesan kaku, tidak dinamis. Terdapat hubungan yang kuat antara inovasi produk dengan pengembangan pasar bank syariah. Artinya, semakin inovatif bank syariah membuat produk, semakin cepat pula pasar berkembang dan lemahnya inovasi produk bank syariah, bagaimanapun berimbas secara signifikan kepada lambatnya pengembangan pasar (market expansion). Lemahnya inovasi produk dan pengembangan pasar (market expansion) bank syariah harus segera di atasi, agar akselerasi pengembangan bank syariah lebih cepat. Inovasi produk diperlukan agar bank syariah bisa lebih optimal dalam memanfaatkan fenomena global. Karena itu harus melakukan inisiatif akselerasi luar biasa dalam pengembangan pasar dan pengembangan produk. ${ }^{1}$

Salah satu pilar penting untuk menciptakan produk perbankan dan keuangan syariah dalam menjawab tuntutan kebutuhan masyarakat modern adalah pengembangan multi akad (hybrid contract/al-'uqud al-murakkabah). Bentuk akad tunggal sudah tidak mampu meresponi transaksi keuangan kontemporer. Sehingga metode hybrid contract seharusnya menjadi unggulan dalam pengembangan produk. Multi akad (hybrid contract) adalah kesepakatan dua pihak untuk melaksanakan suatu muamalah yang meliputi dua akad atau lebih, misalnya satu transaksi yang terdiri dari akad jual beli dan ijarah, akad jual beli dan hibah dan seterusnya, sehingga semua akibat hukum dari akad-akad gabungan itu, serta semua hak dan kewajiban yang ditimbulkannya, dianggap satu kesatuan yang tak dapat dipisah-pisahkan, yang sama
Agustianto, "Inovasi Produk Perbankan Syariah Dari Aspek Pengembangan Fikih Muamalah", https://shariaeconomics.wordpress.com/2011/10/13/inovasi-produk- diakses 
kedudukannya dengan akibat-akibat hukum dari satu akad. Kombinasi produk pembiayaan ini dilakukan sebagai proses kreativitas dari bank syariah dalam mengembangkan produk perbankan syariah dengan skema akad IMBT, MMQ, Qardh wa al-Ijarah, Wakalah wa al-Murabahah, Wakalah bi al-Ujrah, dll.

Hybrid contract sebenarnya bukanlah teori baru dalam khazanah Fiqh Muamalah. Para ulama klasik Islam sudah lama mendiskusikan topik ini berdasarkan dalil-dalil syara' dan ijtihad yang shahih. Namun, dalam kajian Fiqh Muamalah di Pesantren bahkan di Perguruan Tinggi Islam, isu ini kurang banyak dibahas, karena belum banyak bersentuhan dengan realita bisnis di masyarakat. Pada masa kemajuan lembaga keuangan dan perbankan di masa sekarang, konsep dan topik hybrid contract kembali mengemuka dan menjadi teori dan konsep yang tak terelakkan karena dalam beberapa transaksinya perbankan syariah menerapkannya.

Tanpa memahami konsep dan teori hybrid contract, maka seluruh stake holders ekonomi syariah akan mengalami kesalahan dan kefatalan, sehingga dapat menimbulkan kemudhratan, kesulitan dan kemunduran bagi industri keuangan dan perbankan syariah. Semua pihak yang berkepentingan dengan ekonomi syariah, wajib memahami dan menerapkan konsep ini, mulai dari dirjen pajak, regulator (BI dan OJK), bankers/praktisi LKS, dosen (akademisi), Dewan Pengawas Syariah, notaris, auditor, akuntan, pengacara, hakim, dan sebagainya. Jadi semua pihak yang terkait dengan ekonomi dan keuangan syariah wajib memahami teori dan praktik ini dengan tepat dan dengan baik.

Hybrid contract sangat terkait dengan inovasi produk. Bank syariah yang ingin mengembangkan dan menginovasi produk harus memahami teori hybrid contract agar bank syariah bisa unggul dan dapat bersaing dengan konvensional. Dengan demikian, peranan hybrid contract sangat penting bagi insdustri perbankan dan keuangan. Jangan sampai terjadi bankir syarîe ah menolak peluang yang halal karena kedangkalan keilmuan tentang teori-teori pengembangan akad-akad syariah. Untuk itu teori hybrid contract harus digunakan dan difahami dengan baik agar bank syariah bisa lebih kreatif dan inovatif dalam mengembangkan produk-produknya. Selain itu hybrid contract terkait dengan manajemen risiko, termasuk risiko hukum, karena itu praktisi bank syariah mutlak harus memahami teori dan praktiknya..

\section{PEMBAHASAN}

\section{A. Pengertian Hybrid Contact.}

Hybrid contract atau dalam bahasa Indonesia disebut dengan multi akad. Multi dalam bahasa Indonesia berarti (1) banyak; lebih dari satu; lebih dari dua; (2) berlipat ganda. ${ }^{2}$ Dengan demikian, multi akad dalam bahasa Indonesia berarti akad berganda atau akad yang banyak, lebih dari satu. Sedangkan menurut istilah Fiqh, kata multi akad merupakan terjemahan dari bahasa Arab yaitu al-'uqud al-murakkabah yang berarti akad ganda (rangkap). Al-'uqud al-murakkabah terdiri dari dua kata al-'uqud (bentuk jamak dari 'aqd) dan almurakkabah. Kata 'aqd secara etimologi artinya mengokohkan, meratifikasi dan mengadakan perjanjia. ${ }^{3}$ Sedangkan secara terminologi 'aqd berarti mengadakan perjanjian atau ikatan yang mengakibatkan munculnya kewajiban.

Menurut Wahbah az-Zuhaili, 'aqd adalah: "Pertalian atau perikatan antara ijab dan qabul sesuai dengan kehendak syariah yang menetapkan adanya akibat hukum pada objek perikatan." Kata al-murakkabah (murakkab) secara etimologi berarti aljam'u (mashdar), yang berarti pengumpulan atau penghimpunan. ${ }^{5}$ Kata murakkab sendiri berasal dari kata "rakkaba yurakkibu tarkiban" yang mengandung arti meletakkan sesuatu pada sesuatu yang lain sehingga menumpuk, ada yang di atas dan yang di bawah.

Sedangkan murakkab menurut pengertian para ulama Fiqh adalah sebagai berikut:

1. Himpunan beberapa hal, sehingga disebut dengan satu nama. Seseorang menjadikan beberapa hal menjadi satu hal (satu nama) dikatakan sebagai melakukan penggabungan (tarkib)

2. Sesuatu yang dibuat dari dua atau beberapa bagian, sebagai kebalikan dari sesuatu yang sederhana (tunggal/ basith) yang tidak memiliki bagian-bagian.

3. Meletakkan sesuatu di atas sesuatu lain atau menggabungkan sesuatu dengan yang lainnya

Ketiga pengertian ini memiliki kelebihan dan kekurangan masing-masing untuk menjelaskan makna persis dari istilah murakkab. Pengertian pertama lebih tepat untuk digunakan karena mengandung dua hal sekaligus, yaitu terhimpunnya beberapa hal dan bersatunya beberapa hal itu yang kemudian menjadi satu pengertian tertentu. Pengertian kedua tidak menjelaskan akibat dari terhimpunnya beberapa hal itu. Meski pengertian kedua menyatakan adanya gabungan dua atau beberapa hal, tetapi tidak menjelaskan apa dan bagaimana setelah terjadi penggabungan tersebut. Pengertian terakhir lebih dekat kepada pengertian etimologis, tidak menjelaskan pengertian untuk suatu istilah tertentu. Dengan demikian pengertian pertama lebih dekat dan pas untuk menjelaskan maksud al-'uqud al-murakkabah dalam konteks fikih muamalah. Karena itu, akad murakkab menurut Nazih Hammad adalah: 6 "Kesepakatan dua pihak untuk melaksanakan suatu akad yang mengandung dua akad atau lebih -seperti jual beli dengan sewa menyewa, hibah, wakalah, qardh, muzara'ah, sahraf (penukaran mata uang), syirkah, mudharabah, dst. sehingga semua akibat hukum akad-akad yang terhimpun tersebut, serta semua hak dan kewajiban yang ditimbulkannya dipandang sebagai satu kesatuan yang tidak dapat dipisah-pisahkan, sebagaimana akibat hukum dari satu akad." Sedangkan menurut Al-'Imrani, akad murakkab adalah "Himpunan beberapa akad kebendaan yang dikandung oleh sebuah akad baik secara gabungan maupun secara timbal balik sehingga seluruh hak dan kewajiban yang ditimbulkannya dipandang sebagai akibat hukum dari satu akad."

Kedua definisi di atas tampaknya mirip dan tidak terdapat perbedaan. Hybrid contract itu dipandang sebagai satu kesatuan akad dan semua akibat hukum akad-akad yang tergabung tersebut, serta semua hak dan kewajiban yang ditimbulkannya dipandang sebagai satu kesatuan yang tidak dapat dipisah-pisahkan, sebagaimana akibat hukum dari satu akad.
2 Tim Penyusun, Kamus Besar Bahasa Indonesia, (Jakarta: Balai Pustaka, 1996), 671.

${ }^{3}$ Ahmad Warson Munawwir, Kamus Al-Munawwir Arab - Indonesia Terlengkap, (Surabaya: Pustaka Progresif, 1997), 953.

4 Muhsin Haryanto, "Multi Akad ((Al-'Uqûd Al-Murakkabah/Hybrid Contracts)) Dalam Transaksi Syari'ah Kontemporer Pada Lembaga Keuangan Syari'ah Di Indonesia: Konsep dan Ketentuan (Dhawabith) Dalam Perspektif
Fiqh",http://muhsinhar.staff.umy.ac.id/multi-akad-al-uqud-almurakkabahhybrid-contracts-dalam-transaksi-syariah-kontemporer-padalembaga-keuangan-syariah-di-indonesia/, diakses tanggal 29 Mei 2017.

${ }^{5}$ Ahmad Warson Munawwir, Kamus Al-Munawwir, 209.

${ }^{6}$ Hasanudin, Multi Akad Dalam Transaksi Syariah Kontemporer Pada Lembaga Keuangan Syariah di Indonesia, (Ciputat: UIN Syahid, 2009), 3. 
Menurut asy-Syatibi, penelitian terhadap hukum Islam menunjukkan bahwa dampak hukum dari hybrid contract tidak sama seperti saat akad itu berdiri sendiri-sendiri. Akan tetapi harus dicatat, meskipun sudah menjadi satu kesatuan, dalam pembuatan draft kontrak, akad-akad yang tergolong hybrid tersebut ada yang dapat digabungkan dalam satu title kontrak dan ada pula yang dipisahkan. Untuk musyarakah mutanaqishah, akad syirkah milk, dibuat terpisah dengan akad ijarah, demikian pula akad pembiayaan take over, masingmasing akadnya dipisahkan, namun dipandang sebagai satu kesatuan.

\section{B. Landasan Fiqh dan Pendapat Ulama}

Persoalan hybrid contract berkembang dari teori bahwa syariah tidak membolehkan dua akad dalam satu transaksi akad (two in one). Padahal, larangan two in one terbatas dalam tiga kasus saja sesuai dengan hadits Nabi Muhammad SAW yang terkait larangan penggunaan hybrid contract. Ketiga hadits itu berisi tiga larangan, pertama larangan bai' dan salaf, kedua, larangan bai'ataini fi bai'atin, dan ketiga larangan shafaqataini fi shafqatin.

"Rasulullah SAW melarang dua akad dalam satu transaksi karena di dalamnya terdapat suatu kesamaran, tipuan, kelaliman, aib, kerancuan pada ungkapan penawaran dan besar kemungkinan terjadinya kecurangan." Diriwayatkan Ahmad dalam kitabnya Musnad, dari Abdullah bin Mas'ud bahwa Rasulullah SAW melarang dua akad dalam satu transaksi.

Rasulullah SAW bersabda, "Tidak halal dua syarat yang ada dalam jual beli". (HR Abu Dawud dan Tirmidzi). Imam Ahmad dalam kitabnya Al-Mughni berkata, "Dilarang dua syarat dalam satu akad jual beli".

Imam Malik dalam kitabnya Al-Muwaththa' berkata, "Yahya meriwayatkan kepadaku dari Malik, ia telah mendapat kabar bahwa Rasulullah SAW melarang dua jual beli dalam satu transaksi.

Kasus pertama yang dilarang, adalah menggabungkan akad qardh dengan jual beli sesuai dengan sabda Nabi Muhammad SAW tentang hal tersebut. "Dari Abu Hurairah, Rasulullah SAW melarang jual beli dan pinjaman”. (HR. Ahmad).

Kasus Kedua, bai' al-'inah, pendapat ini dikutip dari pandangan Ibnu Qayyim yang menyatakan, bahwa dari 14 penafsiran terhadap hadits bai'atain fi bai'atin (dua akad dalam satu transaksi), penafsiran yang paling shahih adalah bai' al'inah tersebut.

Kasus ketiga yang dilarang, adalah penjual menawarkan dua harga atau beberapa harga kepada pembeli, misalnya, harga barang jika kontan Rp. 10 juta, jika cicilan Rp. 12 juta, kemudian pembeli menerima (mengucapkan qabul), tanpa terlebih dahulu memilih salah satu harganya, Bentuk jual beli ini dilarang karena tidak jelas harganya (gharar). Itulah tiga kasus hybrid contract yang dilarang berdasarkan hadits Nabi SAW.

Aliudin Za'tary dalam buku Fiqh Muamalah Al-Maliyah alMuqaran mengatakan "Tidak ada larangan dalam syariah tentang penggabungan dua akad dalam satu transaksi, baik akad pertukaran (bisnis) maupun akad tabarru'. Hal ini berdasarkan keumuman dalil-dalil yang memerintahkan untuk memenuhi (wafa) syarat-syarat dan akad-akad". Dengan demikian, hukum multi akad adalah boleh.
Mayoritas ulama Hanafiyah, sebagian pendapat ulama Malikiyah, ulama Syafi'iyah, dan Hanbali berpendapat bahwa hukum hybrid contract adalah sah dan diperbolehkan menurut syariat Islam. Ulama yang membolehkan beralasan bahwa hukum asal dari akad adalah boleh dan sah, tidak diharamkan dan dibatalkan selama tidak ada dalil hukum yang mengharamkan atau membatalkannya. Kecuali menggabungkan dua akad yang menimbulkan riba atau menyerupai riba, seperti menggabungkan qardh dengan akad yang lain, karena adanya larangan hadits menggabungkan jual beli dan qardh. Demikian pula menggabungkan jual beli cicilan dan jual beli cash dalam satu transaksi.

Nazih Hammad dalam buku al- 'Uqud al-Murakkabah fi alFiqh al-Islâmy menuliskan, "Hukum dasar dalam syara' adalah bolehnya melakukan transaksi hybrid contract, selama setiap akad yang membangunnya ketika dilakukan sendiri-sendiri hukumnya boleh dan tidak ada dalil yang melarangnya. Ketika ada dalil yang melarang, maka dalil itu tidak diberlakukan secara umum, tetapi mengecualikan pada kasus yang diharamkan menurut dalil itu. Karena itu, kasus itu dikatakan sebagai pengecualian atas kaidah umum yang berlaku yaitu mengenai kebebasan melakukan akad dan menjalankan perjanjian yang telah disepakati.

Pendapat-pendapat di atas didasarkan pada beberapa nash yang menunjukkan kebolehan multi akad atau hybrid contract dan akad secara umum. Misalnya sebagaimana yang tertuang dalam Q.S. al-Maidah ayat 1 yang artinya: "Wahai orang-orang yang beriman penuhilah olehmu akad-akad itu".

Dengan demikian baik itu para dosen, ahli ekonomi syariah dan para banker syariah serta para konsultan harus mempelajari kembali secara mendalam pandangan-pandangan ulama tentang akad two in one, multiakad atau hybrid contract agar pemahaman terhadap desain kontrak syariah, bisa lebih konfrehensif, dinamis dan tidak kaku.

\section{Macam-Macam Hybrid Contract}

Abdullah al-'Imrani dalam buku al-Uqud al-Maliyah alMurakkabah membagi hybrid contract menjadi sebagai berikut: ${ }^{8}$

1. Hybrid contract yang mukhtaliyah (bercampur) yang memunculkan nama baru seperti bai' istighlal, bai' tawarruq, musyarakah mutanaqishah dan bai' wafa'. Jual beli istighlal merupakan percampuran 3 (tiga) akad, yakni 2 (dua) akad jual beli dan ijarah, sehingga bercampur 3 (tiga) akad. Akad ini disebut juga three in one. Jual beli tawarruq percampuran 2 (dua) akad jual beli. Jual beli 1 (pertama) dengan pihak pertama, jual beli kedua dengan pihak ketiga. Sementara musyarakah mutanaqishah merupakan akad akad campuran antara akad syirkah milik dengan ijarah yang mutanaqishah atau jual beli yang disifati dengan mutanaqishah (decreasing). Percampuran akad-akad ini melahirkan nama baru, yakni musyarakah mutanaqishah. Sementara itu substansi akad ini sama dengan ijarah muntahia bit tamlik (IMBT), karena pada akhir periode, barang menjadi milik nasabah, namun bentuk ijarahnya berbeda, karena transfer of title ini bukan dengan janji hibah atau beli, tetapi karena transfer of title yang mutanaqishah, karena itu sebutannya ijarah saja, bukan IMBT.

\footnotetext{
7 Agustianto, "Inovasi Produk Perbankan Syariah Dari Aspek Pengembangan Fiqh

https://shariaeconomics.wordpress.com/2011/10/13/.

Muamalah",
}

8 Hermansyah, "Inovasi Produk Perbankan $\begin{gathered}\text { Syariah", } \\ \text { https://www.academia.edu/9446205/Inovasi_Produk_Perbankan_Syariah, }\end{gathered}$
diakses tanggal 29 Mei 2017. 
2. Hybrid contract yang mujtami'ah atau mukhtalitah dengan nama akad baru, namun menyebut nama akad yang lama, seperti sewa beli (bai' at-takjiry) lease and purchase. Contoh lain yakni mudharabah musyarakah pada life insurance dan deposito bank syariah. Contoh lain yang cukup menarik adalah menggabungkan akad wadi'ah dengan akad mudharabah pada produk giro, yang biasa disebut tabungan dan giro automatic transfer mudharabah dan wadi'ah. Dalam hal ini, nasabah memiliki dua rekening yakni tabungan dan giro sekaligus (dua rekening dalam satu produk). Setiap rekening dapat pindah secara otomatis jika salah satu rekening membutuhkan.

Contoh lain lagi adalah sewa beli (lease and purchase). Menurut Usman Tsabir dalam buku Fiqh Muamalah alMu'ashirah, sewa beli hukumnya boleh, tidak terdapat gharar padanya. Menurut Tsabir, para ulama berbeda pendapat tentang hukum menggabungkan dua akad yakni antara akad jual beli dan ijarah. Sebagian ulama mengatakan boleh, yakni ulama Malikiyah dan Imam Syafi'iyah dalam salah satu pendapatnya, juga Qadhi (Hakim Agama) dari ulama Hanabilah sebagian ulama mengatakan tidak boleh, yakni Hanafiyah, Zhahiriyah, Mazhab Syafi'iy dan al-Kharqy dari Hanabilah.

Selanjutnya Dr. Usman Tsabir mentarjih sebagai berikut: "tetapi pendapat yang paling kuat adalah pandangan yang membolehkan. Inilah pendapat yang paling nyata (realistis), karena barang (obyek) yang dibeli dan jasa yang dilakukan, keduanya membutuhkan iwadh', bisa berlaku masing-masing dan bisa pula digabung sekaligus".Perbedaan sewa dan beli tidak merusak sahnya akad. Karena perbedaan hukum (ketentuan) dua akad tidak mencegah sahnya akad. Diantara dalil yang menguatkan pandapat yang membolehkan penggabungan akad jual beli dan ijarah (two in one) adalah kaidah dasar dalam pertukaran, tidak ada dalil yang mengharamkannya. Hukumnya boleh karena dasar istishab.

1. Hybrid contract yang akad-akadnya tidak bercampur dan tidak melahirkan nama akad baru. Tetapi nama akad dasarnya tetap ada dan eksis dan dipraktekkan ke dalam suatu transaksi, misalnya:

a. Kontrak akad pembiayaan take over pada alternatif 1 dan 4 pada fatwa DSN MUI No.31 tahun 2002.

b. Kafalah wal ijarah serta qardh dan ijarah pada kartu kredit.

c. Wa'ad untuk wakalah murabahah, ijarah, musyarakah dan lainnya pada pembiayaan rekening koran atau line facility.

d. Murabahah wal wakalah pada pembiayaan murabahah basithah.

e. Wakalah bil ujrah pada L/C, RTGS, genaral insurance, dan factoring.

f. Kafalah wal ijarah pada L/C, bank garansi, pembiayaan multijasa atau multiguna dan kartu kredit.

g. Mudharabah wal murabahah atau ijarah atau istisna' pada pembiayaan terhadap karyawan koperasi instansi.

h. Hiwalah dan syirkah pada factoring.

i. Rahn wal ijarah pada REPO, SBI, dan SPN dan SBSN.

j. $\quad$ Qardh, rahn dan ijarah pada produk gadai emas di bank syariah

Dalam transaksi pasar uang antar bank syariah yang menggunakan bursa komuditas dibutuhkan 5 (lima) akad yakni: (1) akad bai' antara bank surplus (peserta komersial) dengan pedagang komoditas; (2) akad murabahah antara bank surplus dengan bank defisit (konsumen komoditas); (3) akad bai' antara bank defisit dengan pedagang komoditas; (4) wakalah antara bank defisit kepada agen atau bursa berjangka Jakarta (BBJ); (5) akad bai' muqayyadhah antara sesama pedagang komoditas.

2. Hybrid contract yang mutanaqidhah (akad-akadnya berlawanan). Bentuk ini dilarang dalam syariah. Misalnya menggabungkan jual beli dan pinjaman (bay wa salaf). Contoh lain, menggabungkan qardh wal ijarah dalam satu akad. Kedua contoh tersebut dilarang oleh nash (dalil) syariah, yakni hadis Rasulullah SAW. Contoh yang lain lagi adalah menggabungkan antara qardh dengan janji hadiah.

3. Hybrid contract yang mustatir (tersembunyi). Misalnya tabungan mudharabah di bank syariah. akad yang digunakan pada saat transaksi hanyalah satu akad yakni mudharabahah. Namun sebenarnya, dalam akad tersebut tidak cukup hanya satu akad, harus ada akad lain sebagai tambahan, yakni kafalah, karena ketika nasabah menarik dana di automatic teller mechine (ATM) bersama, bukan ATM bank bersangkutan, dipelukan akad kafalah. Namun akad tersebut tidak disebutkan, melainkan tersembunyi (mustatir) karena sudah menjadi 'urf perbankan, dimana setiap tabungan, dapat ditarik di ATM tertentu (termasuk ATM bersama).

Dalam sukuk ijarah, sebenarnya terdapat tiga akad yakni akad bai' (bai' al-manfa'ah), akad ijarah dan akad bai' kembali. Namun dalam penamaan biasanya disebut sukuk ijarah saja.

Dalam praktek legal (hukum) di lembaga keuangan syariah (LKS), ada hybrid contract yang akad-akadnya harus dipisahkan dan ada pula yang boleh disatukan dalam satu dokumen (satu materai). Akad syirkah muntanaqishah harus dipisahkan akad-akadnya, akad pertama ialah syirkah milik, dan akad kedua ialah ijarah yang husus. Semua ulama mengharuskan terpisahnya kedua akad tersebut.

Dalam gadai syariah terdapat tiga akad, yakni rahn, qardh (dayn) dan ijarah. Akad rahn dan dayn (janji hutang) boleh disatukan, karena memang harus bersatu dalam satu kertas. Sedangkan akad ijarah sebaiknya dipisahkan untuk menghindari kesan penafsiran ijarah itu atas dasar hutang (qardh). Ijarah tidak terkait dengan qardh, melainkan terkait dengan penyewaan tempat, keamanan barang gadai dan sebagainya.

Demikian halnya dalam kartu kredit terdapat tiga akad, yakni kafalah dan ijarah saat pembelian barang di merchant, dan kedua akad qardh dan ijarah, ketika penarikan uang.

Dalam pembiayaan take over banyak sekali alternatif hybrid contract di dalamnya berdasarkan fatwa DSN MUI No. 31 tahun 2002. Antara lain, gabungan akad qardh, bai' dan ijarah muntahia bit tamlik (IMBT) atau murabahah. Jika menggunakan akad murabahah, mirip dengan bai' al-inah, maka seharusnya dihindari. Akad bai' dalam pembiayaan take over dapat dilakukan di bawah tangan (secara fiqih saja, tanpa notaris), karena hanya sebagai bridging of financing. Peran notaris hanyalah ketika akad murabahah berlangsung.

Demikian pula dalam praktik hedging (tahawwut) melalui islamic swap, akadnya juga hybrid, pertama dapat 
EKSISBANK Vol. 2 No. 2 Desember 2018

menggunakan double qardh, kedua sharf biasa dan wa'ad, ketiga tawarruq timbal balik (double tawarruq). Semuanya adalah hybrid contract. 


\section{KESIMPULAN}

Di lembaga keuangan syariah, sebuah produk yang ditawarkan akan senantiasa melekat dengan akad yang menyertaianya. Hal ini didasarkan bahwa posisi akad dalam produk perbankan syariah menjadi penentu keabsahan transaksi. Dengan kata lain, sah tidaknya sebuah transaksi akan sangat ditentukan oleh akad yang menyertainya.

Hybrid Contract sebenarnya bukanlah teori baru dalam khazanah fiqh muamalah. Para ulama klasik Islam sudah lama mendiskusikan topik ini berdasarkan dalil-dalil syara' dan ijtihad yang shahih. Pada masa kemajuan lembaga keuangan dan perbankan di masa sekarang, konsep dan topic hybrid contracts kembali mengemuka dan menjadi teori dan konsep yang tak terelakkan. Sejumlah buku dan karya ilmiah pun bermunculan membahas dan merumuskan teori al-'uqud almurakkabah (hybrid contract) ini.

Tanpa memahami konsep dan teori hybrid contract, maka seluruh stake holders ekonomi syariah akan mengalami kesalahan dan kefatalan, sehingga dapat menimbulkan kemudhratan, kesulitan dan kemunduran bagi industri keuangan dan perbankan syariah. Semua pihak yang berkepentingan dengan ekonomi syariah, wajib memahami dan menerapkan konsep ini, mulai dari Dirjen Pajak, regulator (BI dan OJK), bankers/praktisi LKS, DPS, notaris, auditor, akuntan, pengacara, hakim, dosen (akademisi), dsb. Jadi semua pihak yang terkait dengan ekonomi dan keuangan syariah wajib memahami teori dan praktek ini dengan tepat dan dengan baik.

\section{REFERENSI}

[1] Agustianto. "Inovasi Produk Perbankan Syariah Dari Aspek Pengembangan Fikih Muamalah". https://shariaeconomics.wordpress.com/2011/10/13/inovasi-produkperbankan-syariah-dari-aspek-pengembangan-fikih-muamalah/. (diakses 29 Mei 2017).

[2] Haryanto, Muhsin. "Multi Akad (Al-'Uqud Al-Murakkabah/Hybrid Contracts) Dalam Transaksi Syari'ah Kontemporer Pada Lembaga Keuangan Syari'ah Di Indonesia: Konsep dan Ketentuan (Dhawabith) Dalam Perspektif Fiqh". http://muhsinhar.staff.umy.ac.id/multi-akad-aluqud-al-murakkabahhybrid-contracts-dalam-transaksi-syariah-

kontemporer-pada-lembaga-keuangan-syariah-di-indonesia/. (diakses 29 Mei 2017)

[3] Hasanudin. Multi Akad Dalam Transaksi Syariah Kontemporer Pada Lembaga Keuangan Syariah di Indonesia. Ciputat: UIN Syahid, 2009.

[4] Hermansyah. "Inovasi Produk Perbankan Syariah". https://www.academia.edu/9446205/Inovasi_Produk_Perbankan_Syari ah. (diakses 29 Mei 2017).

[5] Munawwir, Ahmad Warson. Kamus Al-Munawwir Arab - Indonesia Terlengkap. Surabaya: Pustaka Progresif, 1997.

[6] Penyusun, Tim. Kamus Besar Bahasa Indonesia. Jakarta: Balai Pustaka, 1996. 